\title{
Educação superior: processos motivacionais estudantis para a evasão e a permanência
}

\author{
Higher education: students motivational process for dropping out and \\ remaining Educación superior: procesos motivacionales estudiantiles para la \\ evasión y la permanencia
}

\section{BETTINA STEREN DOS SANTOS \\ TÁRCIA RITA DAVOGLIO \\ CARLA DA CONCEIÇÃO LETTNIN \\ CARLA SPAGNOLO \\ LORENA MACHADO DO NASCIMENTO}

\begin{abstract}
Resumo: O estudo analisou os motivos para a evasão e a permanência na Educação Superior apontados por 746 estudantes de uma instituição privada, a maioria cursando entre o $4^{\circ}$ e o $7^{\circ}$ semestre. A partir de questionários semiestruturados e da Análise de Conteúdo, emergiram as categorias 'Universidade', 'Profissional' e 'Pessoal', esta última mostrando-se a mais relevante para a decisão tanto de prosseguir como de abandonar o curso. A categoria 'Universidade' relacionou-se mais à evasão e a 'Profissional' à permanência dos estudantes. Tais resultados retratam uma realidade específica e podem subsidiar novos estudos.
\end{abstract}

Palavras-chave: Educação superior; permanência; evasão.

Abstract: The study analyzed the reasons for dropout and retention in higher education pointed out by 746 students of a private institution, most coursing between the 4th and 7 th semester. Through semi structured questionnaires and content analysis, the categories University, Business and Personal emerged. This latter one proved to be the most relevant for the decision either to continue or to leave the course. The University category was more related to the dropout and the Professional one to the permanence of students. These results portray a specific reality, which can support new studies.

Keywords: Higher education; permanence; dropout.

Resumen: El estudio analizó las razones de la evación y permanencia en la educación superior señaladas por 746 estudiantes de una institución privada, la mayoría cursando entre el $4^{\circ}$ y el $7^{\circ}$ semestre. Con base en cuestionarios semiestructurados y en el análisis de contenido, surgieron las categorías Universidad, Profesional y Personal, esta última se demostró como la más relevante para la decisión tanto de seguir como de abandonar el curso. La categoría de la universidad se relacionó más con la evasión y la profesional a la permanencia de los estudiantes. Estos resultados representan una realidad específica, que puede apoyar nuevos estudios.

Palabras clave: Educación superior; permanencia; evasión. 


\section{INTRODUÇÃO}

O cenário acadêmico contemporâneo, especialmente dos países ditos 'emergentes', tem apresentado situações paradoxais: por um lado, existe o incentivo e o estímulo para o ingresso na Educação Superior e, por outro, o sistema político-educacional mostra-se deficiente para reter estudantes já inseridos nas instituições de Educação Superior (IES). Isso tem mobilizado pesquisadores brasileiros (ALMEIDA, 2008; BAGGI; LOPES, 2011; SANTOS; MOROSINI; COFER, 2014) a estudar essa questão, a fim de compreendê-la.

Os dados do Censo da Educação Superior do Brasil referentes à graduação apontam que, entre 2012 e 2013, o número de estudantes que terminam seus cursos caiu 5,9\% em relação ao número de matrículas (BRASIL, 2013). O Censo evidencia, ainda, que de 2009 até 2013 o número de matrículas nas instituições privadas aumentou consideravelmente (de 3.764 .728 para 4.374.431); o número de concluintes nesse mesmo período, porém, não acompanhou esse crescimento de modo linear, tendo apresentado, ao contrário, um declínio de 639.124 em 2012 para 623.677 em 2013.

Nessa discrepância entre ingressantes e concluintes evidenciada no Censo, parece ser onde se inserem as questões referentes à evasão universitária, um fenômeno complexo envolvendo os sujeitos e o sistema educacional, com consequências individuais, sociais, acadêmicas e econômicas. Tendo em vista a importância do assunto, a evasão ou a permanência têm sido objeto de investigações em todo o mundo, em relação às quais se busca aprofundar os motivos, as causas e os impactos provenientes do abandono, pelos estudantes, dos sistemas de ensino.

A conceituação e definição do termo 'evasão' não é contudo, unânime. $\mathrm{Na}$ Educação Superior é frequentemente utilizado para se referir, genericamente, à 'perda' ou 'fuga' de alunos da IES (KIRA, 2002). Destacamos, porém, a distinção entre dois conceitos, a partir dessa definição geral (POLYDORO, 2000): evasão do curso e evasão do sistema. A evasão do curso consiste no abandono do mesmo sem sua conclusão, podendo estar implicadas aqui questões de mobilidade do aluno, as quais envolvem, por exemplo, trancamento ou transferência de curso, essas denominadas por Cardoso (2008a) evasão aparente; e a evasão do sistema, que expressa o efetivo abandono do sistema universitário, sendo também nomeada evasão real (CARDOSO, 2008a).

Coadunando com essas definições, no Brasil, o Ministério da Educação (BRASIL, MEC, 1997), por meio da Comissão Especial de Estudos sobre a Evasão nas Universidades Brasileiras, estabeleceu três tipos de evasão: o desligamento do curso superior (abandono propriamente dito); a transferência, trancamento ou 
exclusão pela Instituição de Ensino; e a evasão do sistema, podendo ser definitiva ou temporária. Por outro lado, essa definição também se alinha aos estudos latinoamericanos e europeus sobre evasão, os quais ganharam visibilidade e expansão a partir das Conferencias Latino-Americanas sobre o Abandono na Educação Superior (CLABES), organizadas em parceria com o projeto internacional ALFAGUIA ${ }^{1}$. Coerente com essa abordagem, o conceito de evasão adotado pela IES pesquisada neste estudo segue, em linhas gerais, as definições propostas pelo MEC e pelo Projeto ALFA-GUIA, referindo-se à situação em que o aluno, sem ter terminado seu curso, não realiza matrícula no semestre subsequente ao recém cursado.

Portanto, a evasão, denominada também abandono ${ }^{2}$, em muitos países latino-americanos e europeus que integram esse projeto é caracterizada como a interrupção da relação entre estudante e o curso de graduação antes de se alcançar a titulação. A evasão consiste em "Um evento de caráter complexo, multidimensional e sistêmico, que pode ser entendido como causa e efeito, fracasso ou reorientação de um processo formativo, eleição de respostas forçadas, ou como indicador da qualidade do sistema educativo" (PROYECTO, 2013, p. 6). Partindo desse pressuposto, o conceito abordado reforça as múltiplas dimensões que envolvem o processo da evasão e todas as causas e consequências que afetam os diferentes sujeitos envolvidos, tanto da comunidade acadêmica quanto da sociedade.

Entendemos, assim, que, perante as características e demandas de cada contexto institucional, cultural e social, pode haver mudanças na percepção e nas atitudes que levam à evasão dos estudantes. Acreditamos na necessidade de estudos sobre os processos de evasão produzidos localmente, para que estes reflitam a realidade e as potencialidades de cada IES e de seus respectivos estudantes. As causas e indicadores apontados pela literatura para a evasão acadêmica são relevantes e representam resultados de muitos anos de pesquisas, podendo oferecer diretrizes para o enfrentamento do problema.

O presente estudo tem por objetivo analisar os motivos para a evasão e permanência acadêmica apontados por estudantes de diferentes cursos de graduação de uma IES privada do sul do Brasil. O artigo apresenta, inicialmente,

1 Um projeto financiado pela União Europeia, no qual instituições, organizações e indivíduos de Ensino Superior de 16 países (12 da América Latina e 4 europeus) juntaram-se comprometidos com a meta de reduzir o abandono no ensino superior, com esforço, entusiasmo e conhecimento para trabalhar cooperativamente para três anos (2011-2014) sobre este problema global, o qual afeta negativamente todas as instituições e todos os países. Retirado de http://www.alfaguia.org/www-alfa/index.php/es/

Neste artigo, os termos evasão e abandono serão utilizados como sinônimos 
o cenário atual da pesquisa empírica sobre a temática e, em seguida, descreve os procedimentos empíricos realizados no estudo e os resultados encontrados, debatendo-os a partir da literatura.

\section{A PESQUISA EMPÍRICA SOBRE A EVASÃO}

Há anos estudiosos e pesquisadores têm canalizado esforços para apontar fatores implicados na evasão acadêmica (TINTO, 1975; ROOTMAN, 1972; KARABEL, 1972). Tinto, por exemplo, desde 1975 vem buscando subsídios para compor uma teorização consistente, afirmando, porém, que o campo da pesquisa sobre a evasão se apresenta desordenado pela incapacidade de convergência sobre os tipos de comportamentos denominados abandono (deserción) (TINTO, 1989). Enfatiza a necessidade de uma linguagem comum entre os pesquisadores, tanto na perspectiva semântica quanto operacional. Apesar dessas dificuldades, os estudos empíricos de Tinto apontam que há influência de quatro conjuntos de fatores sobre a decisão do estudante de abandonar a universidade, os quais mesclam tanto elementos individuais, relacionados aos estudantes, quanto institucionais, como elementos ligados às IES e ao contexto educacional como um todo.

É possível também identificar três períodos críticos para a evasão na trajetória dos estudantes. De acordo com Tinto (1989), o primeiro acontece na transição entre o Ensino Médio e o universitário, caracterizando-se pela transição de um ambiente conhecido para um mundo de aparência impessoal. Já o segundo período é reflexo das expectativas equivocadas sobre a instituição e as condições da vida estudantil, que ao não se mostrarem satisfatórias para o estudante, podem conduzir a decepções e, consequentemente, ao abandono. E o terceiro período está relacionado ao rendimento acadêmico, ou seja, quando o estudante não alcança os objetivos nas disciplinas e a instituição não proporciona alternativas para superar as deficiências acadêmicas.

Além disso, encontramos outros subsídios empíricos e teóricos para a compreensão da evasão, mais focados na análise de aspectos individuais relacionados ao próprio estudante. Lobo (2012) afirma, com base em achados empíricos, que diversas dificuldades podem estar na origem do fenômeno: inadaptação do ingressante ao estilo do Ensino Superior e falta de maturidade; formação básica diferente; dificuldade financeira; irritação com a precariedade dos serviços oferecidos pela IES; decepção com a pouca motivação e atenção dos professores; dificuldade com transporte, alimentação e ambientação na IES; mudança de curso e mudanças de residência.

Tais resultados apresentados por Lobo são coerentes com os de outros estudos que se focam na compreensão dos aspectos etiológicos da evasão, tendo 
como elemento central o próprio estudante. A partir da análise qualitativa de produções acadêmicas relacionadas à evasão na Educação Superior no Brasil, baseada em sete publicações nos principais periódicos da área da Educação, no período de 2000 a 2011, Morosini et al. (2012) apresentam uma síntese das principais causas e aspectos que influenciam a evasão universitária: financeiros; escolha do curso; interpessoais; desempenho nas disciplinas e tarefas acadêmicas; sociais; incompatibilidade entre os horários de estudo e as demais atividades; familiares; e baixo nível de motivação e compromisso com o curso.

O Relatório ALFA-GUIA (PROYECTO, 2013) também destaca os fatores individuais mais influentes na decisão de abandono:

Problemas econômicos para o desenvolvimento de estudos; dificuldade para conciliar trabalho e estudo; orientação escolar e profissional inadequada na escolha da carreira; problemas pessoais e/ou familiares (não-econômicos); a falta de motivação pessoal para estudos; baixo rendimento acadêmico; falta de apoio institucional; a falta de conhecimento prévio exigido no ensino superior; insatisfação com o programa ou currículo (p. 51).

Para Barrera, Casallas e Sastre (2015), a maioria dos que abandonam a universidade continuam estudando em outras universidades, e estes são os casos de abandono definitivo da instituição. Por outro lado, o abandono do sistema geralmente envolve razões socioeconômicas e a existência de vínculo laboral. Outro fator relevante é a prioridade para os compromissos familiares; todavia, essas pessoas mantêm a esperança de regressar à universidade a médio prazo, caso as condições, tanto pessoais quanto institucionais, sejam favoráveis para que isso aconteça.

De fato, os fatores que incidem sobre o abandono são múltiplos, simultâneos e correlacionados, como apontam Fiegehen, Díaz e Fernández (2013). Para esses autores, o primeiro conjunto de fatores que envolve a evasão são de caráter pessoal e sociológico; o segundo conjunto corresponde a fatores do âmbito acadêmico, organizacional e disciplinar. O terceiro diz respeito aos fatores externos, sociais, culturais e acadêmicos, de caráter sistêmico. Assim, destacase que a interrupção dos estudos tem consequências que afetam os estudantes em aspectos afetivos, sociais, laborais e econômicos, implicando tanto o âmbito pessoal, como social e o institucional.

Algumas medidas propostas para o enfrentamento da evasão estão alinhadas a esses pressupostos. Por exemplo, o relatório ALFA-GUIA (PROYECTO, 2013) aponta que são possíveis e necessárias algumas intervenções para o estabelecimento de políticas de incentivo à redução das taxas de evasão no ensino superior, aumentando, assim, a correta aplicação dos recursos públicos em benefício da qualidade da Educação Superior. Entre essas medidas, são sugeridas: 
apoio financeiro aos estudantes através de bolsas e empréstimos; orientação adequada, tanto sobre as características e os estudos de carreira, como sobre as atitudes e habilidades necessárias para segui-la com êxito; criação de programas acadêmicos mais flexíveis, permitindo horários compatíveis com a atividade laboral e ritmo adequado à continuidade dos estudos conforme as circunstâncias pessoais do estudante.

Observamos, então, que, embora a maioria dos estudos sobre a evasão ressalte os aspectos individuais relacionados ao estudante como motivadores, a abordagem sistêmica da questão não deve ser negligenciada. Ainda que a evasão se manifeste no comportamento do estudante, esse fenômeno pode originar-se de questões muito além do seu domínio ou com elas imbricadas. Nessa perspectiva, as IES e as políticas educacionais interagem com os estudantes numa relação recíproca, sendo justo e oportuno que a leitura dessa realidade transpasse as contingências do indivíduo, incluindo fatores relacionados às instituições e entidades, de tal modo que a responsabilidade pela mudança do cenário não se limite ao campo das ações individuais

\section{MÉTODO}

Esta pesquisa qualitativa está inserida em um projeto mais amplo sobre permanência, evasão e motivação discentes na Educação Superior. Foi realizada com amostra de 746 estudantes que frequentavam ${ }^{3}$ os cursos de Engenharias, Tecnologia da Informação, Enfermagem, Educação Física, Matemática, Psicologia, Direito, Pedagogia e Letras de uma IES privada do Sul do Brasil, sendo os dados coletados no período de junho a setembro de 2013. Após a aprovação dos protocolos de pesquisa, iniciou-se a coleta de dados, realizada durante uma das aulas frequentadas, previamente acordada com o professor responsável. Os pesquisadores informaram os objetivos e as implicações da pesquisa e apenas os estudantes que se dispuseram a participar voluntária e anonimamente, concordando em assinar o termo de consentimento livre e esclarecido, foram incluídos no estudo.

Como instrumento de coleta foram utilizadas duas questões abertas respondidas pelos discentes: (1) Você desistiu de algum curso superior? (2) Pensa ou pensou em abandonar o curso de graduação que frequenta atualmente? Em ambas as questões, os alunos foram solicitados a justificar sua resposta, fosse ela positiva ou negativa. Os dados qualitativos oriundos dessas questões constituíram

\footnotetext{
3 Foram incluídos na amostra apenas os estudantes que permaneciam nos cursos, visando a identificar fatores atuais da permanência e intenção de evasão, com fins de subsidiar ações preventivas. Portanto, não foi considerado de modo destacado o contingente de evadidos da instituição em pauta.
} 
o corpus da pesquisa e foram submetidos aos princípios da Análise de Conteúdo, conforme Moraes (1998). A partir dessa análise, construíram-se categorias e subcategorias, as quais serviram de base para a compreensão do fenômeno estudado, visando a conhecer a percepção dos discentes sobre a temática.

Ressalta-se que o processo de análise, conforme Moraes (1998), pressupõe cinco etapas: (1) 'preparação das informações' - fase em que organizamos o corpus, realizamos a leitura das respostas e codificamos a amostra; (2) 'desconstrução e unitarização' - as justificativas descritas pelos estudantes foram desmontadas e reorganizadas em unidades de análise, definidas, nesta pesquisa, por frases e/ou palavras-chaves que representavam a ideia; (3) 'categorização' - entendida como o agrupamento das unidades de análise. Assim, as unidades de análise agrupadas foram definidas por categorias temáticas emergentes, ou seja, identificamos posteriormente em cada agrupamento aquilo que o corpus trouxe sobre a permanência e/ou evasão na percepção dos estudantes. Moraes caracteriza a fase de categorização como um trabalho exaustivo na busca de categorias válidas e pertinentes que devem ser homogêneas e consistentes. Portanto, as categorias podem ser criadas em uma fase inicial, intermediária ou final, ou seja, as unidades de análise devem ser classificadas e reclassificadas até que se esgotem as possibilidades de integração e (re)categorização, a fim de constituir um menor número de categorias, de forma que a final seja a mais abrangente possível; (4) 'descrição' - de forma qualitativa, considerando a frequência das respostas apresentadas, as categorias foram descritas de modo a representar o conjunto de significados que as compõem na opinião dos discentes sobre a evasão e/ou permanência; (5) 'interpretação’ - análise crítica desse resultado diante da fundamentação teórica existente e da realidade investigada, ressaltando aquilo que se compreende da opinião dos participantes da pesquisa sobre o fenômeno estudado.

\section{RESULTADOS E DISCUSSÃO}

A amostra foi composta por 746 estudantes (316 (42,4\%) homens e 430 $(57,6 \%)$ mulheres), cuja média de idade foi de 24,4 anos (DP $=6,6)$, cursando entre o quarto e o sétimo semestre do curso de graduação. A faixa etária de até 25 anos foi a que apresentou maior incidência (75\%), seguida da faixa de 26 a 35 anos $(17 \%)$, da de 36 a 45 anos (6\%), tendo sido a de menor incidência a faixa acima de $46 \operatorname{anos}(2 \%)$. Do total de estudantes, apenas $12,7 \%$ informou ter filhos, variando de 1 a 5 . Entre os que informaram a forma de ingresso na universidade ( $n=741)$, a maioria $(63,1 \%)$ ingressou através do vestibular tradicional. O ingresso por meio do ENEM foi a segunda forma mais indicada (31,6\%), seguida pela prova de 
redação $(3,2 \%)$. Outras formas, como ingresso por graduação concluída $(0,5 \%)$ e cotas do vestibular $(0,8 \%)$, também foram relatadas por alguns estudantes. Para a maioria dos estudantes (41,4\%), a família é responsável pelo custeio das mensalidades do curso; os que possuem bolsa ou incentivo empresarial representaram 35,4\%; os demais pagam por meio de financiamento estudantil $(11,5 \%)$ ou com recursos próprios $(10,1 \%)$.

Considerando a análise das razões referidas pelos estudantes sobre a questão discursiva 1 (Você já desistiu de algum curso de graduação?) e questão discursiva 2 (Você pensa ou pensou em abandonar a graduação que frequenta?), foram identificadas e nomeadas três grandes categorias: 'Universidade', 'Pessoal' e 'Profissional'. Essas categorias emergiram a partir da análise das respostas, que apontaram, principalmente, para três direções: a relação dos estudantes com a universidade, a relação dos estudantes com as questões pessoais e a relação dos estudantes com as questões profissionais. Cada categoria se constituiu por diversas subcategorias, como mostra a Figura 1.

Figura 1 - Categorização dos fatores subjacentes à evasão ou à Permanência Discente na Educação Superior.

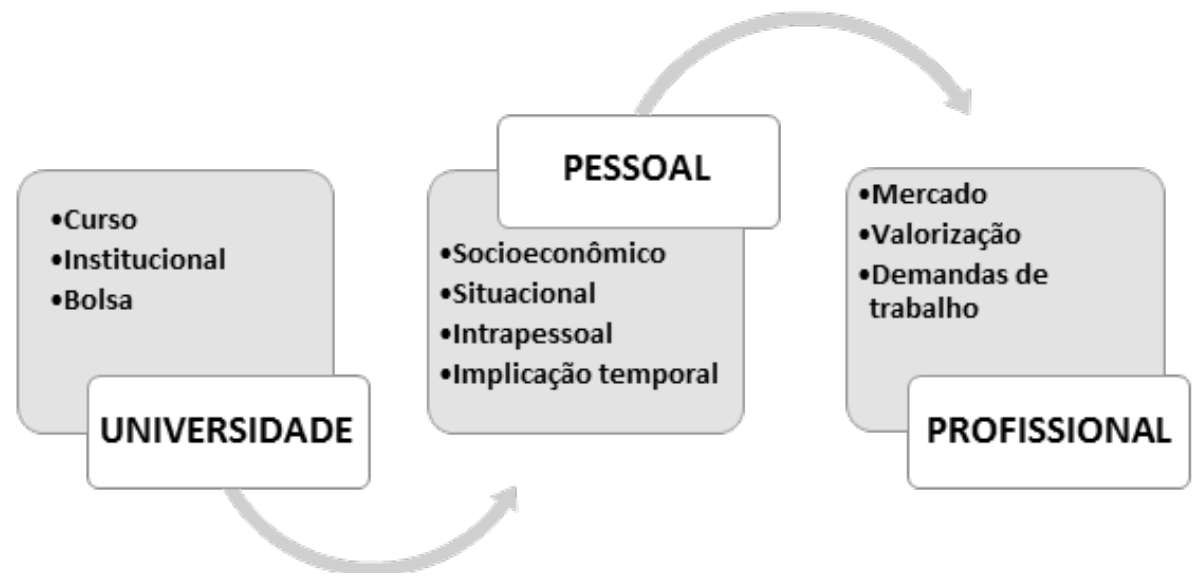

Fonte: Elaboração das autoras.

A categoria 'Universidade' envolveu fatores que constituem a base estrutural, organizacional e funcional da IES, entrelaçando objetivos e princípios institucionais com diretrizes nacionais e internacionais e, principalmente, com fatores ligados à qualidade tanto do curso como da instituição como um todo. Estão incluídas nessa categoria as subcategorias: 
- Curso: As variáveis que compõem esta subcategoria têm relação com a qualidade do curso, os aspectos que compõem o currículo, a metodologia utilizada pelos professores, as exigências do curso anterior ou atual, o conhecimento do curso, as expectativas do aluno em relação ao curso e as experiências vivenciadas em suas disciplinas.

- Institucional: Nesta subcategoria destaca-se a localização, a infraestrutura, a qualidade, o status da universidade, assim como a identificação do aluno com a IES e as opções de funcionamento dos cursos.

- Bolsa: Esta subcategoria está relacionada às oportunidades ofertadas pela universidade e/ou órgãos de fomento que incentivam e auxiliam financeiramente os estudantes.

Outra categoria emergente foi denominada 'Pessoal', representada e justificada por aspectos que dependem de escolhas e circunstâncias de vida de cada pessoa e da responsabilidade que cada um tem sobre as mesmas. Envolve a perspectiva subjetiva do estudante, especialmente no que se refere a sua percepção de determinadas situações. O modo como a pessoa compreende e reage torna-se mais relevante do que os fatos em si, fazendo com que uma mesma situação implique diferentes desfechos. As mudanças e transformações geradas podem ocasionar, simultaneamente, perdas, ganhos e reorganizações em torno de situações já estabelecidas, influenciando mutuamente a permanência ou abandono do curso.

A categoria pessoal foi evidenciada por respostas fundamentalmente relacionadas com problemas pessoais (dificuldades financeiras, identificação com o curso, maturidade, cansaço) e distanciamentos entre o que se busca no curso e as necessidades profissionais (desmotivação, alto investimento no curso), quando se referem à desistência de algum curso. No que diz respeito à permanência dos alunos no curso, as respostas estão vinculadas ao interesse, à determinação e à busca de conhecimento. Mas podem também vincular-se ao aproveitamento de todas as ações realizadas, já que estar no final do curso é a realidade de alguns estudantes, a qual envolveu fatores relacionados diretamente às necessidades, escolhas e situações pessoais que podem surgir na vida do sujeito e influenciar sua trajetória acadêmica. Essa categoria apresentou-se de forma abrangente, contendo as seguintes subcategorias:

- Situacional: Relaciona-se a questões emergenciais e específicas que envolvem relações familiares e pessoais do estudante, tais como, gravidez, mudança de estado civil, de residência, problemas de saúde.

- Intrapessoal: Este indicador é bastante amplo e, ao mesmo tempo, foi uma das subcategorias que apresentou maior número de respostas e itens. Dentre muitos aspectos, ressaltamos a identificação, motivação, interesse, dúvida, gosto, 
expectativas, dificuldades, determinação, realizações, curiosidade, maturidade, valores éticos, reflexão na escolha, perfil da pessoa, percepção de qualidade de vida. Também encontramos nesta subcategoria aspectos relacionados a elementos afetivos e cognitivos, porém numa perspectiva de tempo futuro, tais como crescimento pessoal e profissional, contribuições científicas, continuidade no meio acadêmico e orientação vocacional.

- Implicação temporal: Aborda o tempo de curso já decorrido em relação às ações e esforços empreendidos pelo estudante.

- Socioeconômico: Envolve aspectos de dificuldade econômica ou investimento financeiro na formação acadêmica.

A terceira categoria, intitulada 'Profissional', evidenciou a necessidade de ampliação das atividades profissionais, tendo em vista as crescentes demandas sociais e econômicas impostas pela economia globalizada, dinâmica e cada vez mais competitiva, exigindo conhecimentos específicos de uma mão-de-obra especializada e qualificada, aproximando as pessoas da formação universitária. Diante dessas demandas, as IES enfrentam questionamentos sobre sua atuação e sobre o conhecimento que produzem e oferecem em relação à preparação para o mundo do trabalho e à formação teórico-prática. Aspectos esses que vão impactar não só no modelo de sociedade, como também na evasão ou permanência dos estudantes na Educação Superior, nas suas escolhas e no modo como enfrentam as dificuldades e elaboram os conflitos e ambivalências relacionadas à profissão.

Diante do exposto, a categoria 'Profissional' envolveu aspectos relacionados às demandas profissionais dos estudantes. Essas demandas abrangem tanto as expectativas com relação à futura profissão quanto a possibilidade de conciliá-la com a atividade laboral atualmente exercida.

Nessa perspectiva, surgiram três subcategorias que evidenciam uma postura ativa do estudante diante da formação na profissão pretendida, denominadas:

- Mercado: Esta subcategoria foi demarcada por aspectos ligados às preocupações com a atuação no mercado de trabalho, a busca de estabilidade, a titulação como pré-requisito para o trabalho, atratividade ou saturação do mercado e perspectivas de carreira.

- Demandas de Trabalbo: Esta subcategoria envolve as exigências do trabalho que o aluno exerce, a conciliação das mesmas com os estudos e a priorização do trabalho.

- Valorização: Encontram-se nesta subcategoria os aspectos relacionados com a valorização e desvalorização profissional, remuneração, reconhecimento profissional e social e crescimento profissional. 
A emergência dessas categorias a partir das respostas dos estudantes nos incita a pensar sobre outras dimensões imbuídas do papel da Educação Superior, pois o perfil do estudante na atualidade difere daquele tradicionalmente conhecido: o estudante clássico. Esse estudante ‘clássico’ dispõe de tempo para estudar, tem idade, formação intelectual que transcende os conteúdos curriculares, possui financiamento familiar, disposição para atividades social e culturalmente diversificadas, como apontam Britto, Silva, Castilho e Abreu (2008). Para os autores, o 'novo' perfil de estudante universitário não dispõe de condições apropriadas para estudar, tem pouca convivência com os objetos intelectuais e artísticos da cultura hegemônica; além disso, ainda trabalha durante o dia e assiste a cursos noturnos, com pouca disponibilidade de tempo e recursos para participar de atividades acadêmicas que transcendam o espaço-aula. Assim, mostra-se essencial que as IES ampliem os olhares para o 'novo' perfil de estudante e para todas as necessidades que derivam dessa configuração, as quais interferem em sua permanência na graduação.

Ao considerarmos as frequências das respostas às questões 1 e 2, os resultados deste estudo evidenciaram que, do total de estudantes pesquisados (n = 746), 62,33\% responderam à questão 1 (Você já desistiu de algum curso de graduação?) e, destes, 38,92\% responderam 'sim, já desistiram' apresentando justificativas, totalizando a frequência de 242. Dos 61,07\% que responderam 'não, nunca desistiram' de um curso de graduação, a frequência de justificativas totalizou 234.

Conforme demonstra o Gráfico 1, a categoria 'Pessoal' foi a mais relevante tanto para atribuir significado à resposta 'sim' (59,50\%) como para justificar a resposta 'não' (79,50\%). No entanto, entre os respondentes 'sim' à questão 1, ou seja, para os que já desistiram de algum curso superior, a categoria 'Universidade' foi referida como o segundo fator mais importante $(23,96 \%$ das justificativas), seguida da categoria 'Profissional' (16,53\% das justificativas). O inverso foi observado entre os estudantes que responderam 'não' à questão 1, para os quais a não desistência é atribuída em segundo lugar à categoria 'Profissional' (14,96\% das justificativas) e em terceiro lugar à categoria 'Universidade' (5,98\% das justificativas). 


\section{Gráfico 1 - Frequência de respostas afirmativas e negativas à Questão 1 em cada categoria}

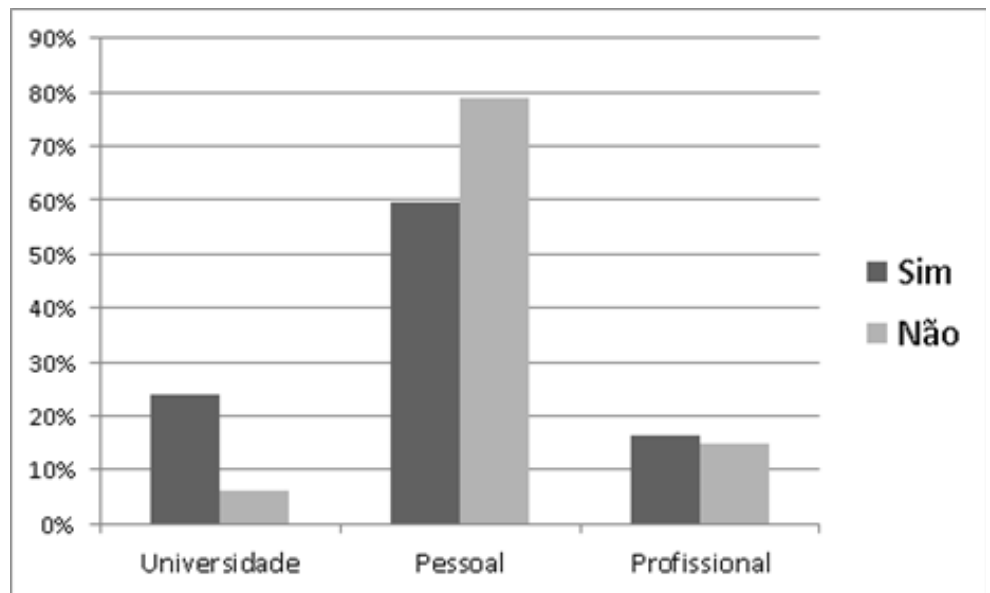

Nota: Baseado no total de respostas afirmativas e respostas negativas de acordo com as categorias (Sim n=181; Não n=284). Fonte: Elaboração das autoras

O Gráfico 2 apresenta os resultados para a questão 2 (Pensa ou pensou em desistir da atual graduação?), a qual foi respondida por $68,90 \%$ do total de estudantes. Entre os respondentes, 44,55\% disseram que 'sim, já pensaram em abandonar o curso atual', e 55,44\% disseram que 'não, nunca pensaram'. Entre as justificativas apontadas, a categoria 'Pessoal' foi a mais frequente tanto para os estudantes que pensam em abandonar quanto para os que não pensam em abandonar o atual curso. Porém, para os estudantes que pensam em abandonar a atual graduação, a categoria 'Universidade' apresentou-se mais relevante que a 'Profissional', sendo o oposto para os que não pensam em abandonar a atual graduação, ou seja, para estes, a categoria 'Profissional' é mais importante que a 'Universidade'. 


\section{Gráfico 2. Frequência de respostas afirmativas e negativas para a Questão 2 em cada categoria}

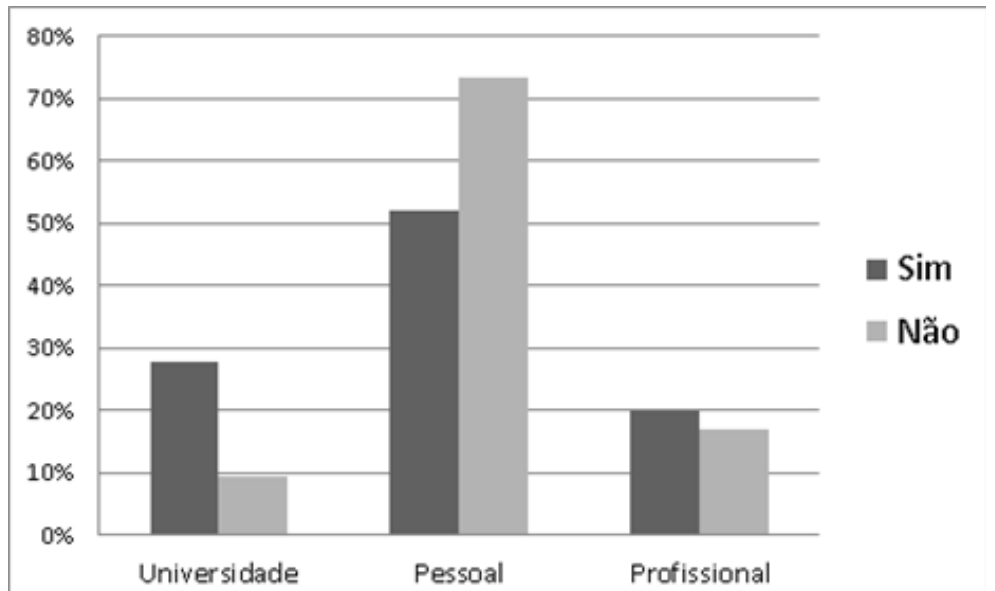

Nota: Baseado no total de respostas afirmativas e respostas negativas de acordo com as categorias (Sim n=229; Não n=285). Fonte: Elaboração das autoras

Portanto, constataram-se diferenças em relação às justificativas para as respostas positivas ou negativas apresentadas na Questão 1 e na Questão 2. Para a Questão1, os motivos atribuídos para as respostas 'Sim, já desisti de um curso superior' e para as respostas 'Não, nunca desisti de um curso superior' se mantiveram na categoria 'Pessoal' para a maioria dos estudantes. Já para a Questão 2, a categoria apontada pela maioria dos estudantes não se manteve a mesma, dependendo de se a resposta foi 'sim' ou' não', variando também conforme o curso atual frequentado pelos estudantes.

Diante desses resultados, pode-se inferir que, de modo global, para os estudantes pesquisados, o abandono ou a intenção de abandono de uma graduação já iniciada esteve ligado primeiro às questões pessoais, depois à universidade e, por último, às questões profissionais. Já para os estudantes que nunca desistiram de uma graduação, as questões pessoais também foram as que mais contaram para a permanência, seguidas das profissionais e, por último, está a universidade. Dessa forma, de modo sumarizado, esta pesquisa revelou três importantes indicadores motivacionais para o abandono/permanência na Educação Superior: (1) as questões pessoais tanto retêm o aluno no curso iniciado como o fazem desistir dele; (2) as questões ligadas à universidade fazem desistir mais do que retêm o aluno; (3) as questões profissionais retêm mais do que fazem desistir da graduação. 


\section{1 - AS QUESTÕES PESSOAIS TANTO RETÊM O ESTUDANTE NA GRADUAÇÃO COMO O FAZEM DESISTIR DELA}

Considerando-se que a maior parte dos estudantes pesquisados estavam na faixa etária inferior a 25 anos, é necessário destacar que os resultados obtidos tendem a se imbricar com as características dessa etapa do ciclo vital. Ao mesmo tempo em que o jovem necessita fazer escolhas em relação a sua carreira profissional, ele ainda está profundamente envolvido com questões inerentes a seu desenvolvimento, à estruturação de sua identidade, a seu papel familiar; enfim, a uma série de demandas de seu processo de amadurecimento psicossocial. Há, portanto, um processo de transição da adolescência para o mundo adulto, no qual características pessoais (interesses, personalidade, identificações, etc.), bem como recursos e apoios de toda ordem, incluindo o social, impactam fortemente sobre a trajetória de vida. Desse modo, questões subjetivas e particulares, categorizadas neste estudo como pessoais, podem tornar-se determinantes frente às decisões a serem tomadas em relação às questões acadêmicas.

Um estudo realizado com o objetivo de analisar a escolha profissional e o direcionamento de carreira de jovens universitários (DIAS; SOARES, 2012) corrobora essa ideia, ao apontar a subjetividade como tendo implicação relevante na trajetória acadêmica.

O processo de direcionamento da carreira está presente em sentidos pessoais e particulares da escolha inicial do curso superior, e a valorização da futura carreira se desloca através de diferentes referenciais, das vivências no contexto universitário e familiar, e, daquilo que dizem para os formandos sobre a profissão, passa-se para um discurso do sujeito que se apropria e ressignifica suas decisões. (p. 279)

Corroborando a ideia de que os fatores pessoais podem fazer diferença tanto para a permanência quanto para a evasão, Matus; Landa; Kuhne e Painepan (2015), expõem resultados de uma investigação com base nos modelos psicológicos, os quais preconizam diferentes teorias para evitar o fracasso acadêmico. Os autores enfatizam a multidimensionalidade de conceitos referentes ao desenvolvimento pessoal e à obtenção do êxito acadêmico, havendo, também, a ação docente como propulsora de estratégias e metodologias de ensino que considerem os estudantes em sua integralidade.

O maior contato com a realidade a partir do acesso a informações mais detalhadas e da construção de novos conhecimentos, o incremento do autoconhecimento decorrente do próprio processo evolutivo e ou de reflexão e da capacidade de pensamento crítico, assim como os eventos inesperados (tais como, desemprego, doenças) ou, até mesmo, normativos da vida (morte, casamento, 
separações, gravidez) contribuem para a ressignificação, após o início do curso, da escolha inicial feita pelo estudante por determinada graduação ou IES. Essa ressignificação tanto pode fortalecer e reafirmar a escolha como pode direcionar para a mudança e o abandono da opção feita.

\section{2 - AS QUESTÕES LIGADAS À UNIVERSIDADE FAZEM O ESTUDANTE DESISTIR MAIS DO QUE O RETÊM}

Parece que a escolha da universidade perpassa diversos fatores internos e externos a ela, envolvendo as expectativas e condições dos estudantes e a realidade oferecida pela instituição. Aspectos funcionais da graduação (currículo, curso, metodologias), qualidade da infraestrutura, localização, status e possibilidades de auxílio financeiro são fundamentais para a permanência dos estudantes dessa pesquisa, pois eles abandonaram seus cursos apontando falhas ou falta desses aspectos.

Por outro lado, o status da instituição e a qualidade do curso, bastante atrelados ao atual sistema de avaliação da Educação Superior (SINAES/INEP), foram os únicos aspectos dessa categoria apontados como determinantes para a permanência. Entende-se que uma IES se qualifica também pelo sistema organizacional que a caracteriza, havendo diferenças nas políticas e recursos entre as Universidades, Centros Universitários, Faculdades ou Institutos e Escolas. No entanto, nem sempre essas diferenças asseguram o atendimento às demandas dos estudantes.

Sabe-se que toda ação carrega um objetivo ou uma finalidade muito peculiar de cada ser humano. Os jovens, ao fazerem suas escolhas acadêmicas, precisam ter suas expectativas atendidas pela IES, além de esta referenciá-lo após a formação. Parece ser uma preocupação do aluno conhecer a realidade do curso e as possibilidades de conhecimentos que essa graduação poderá gerar, o que, muitas vezes, não é explorado pelas IES. Mas também são relevantes a localização, o ambiente e a rotina da instituição, que devem estar em sintonia com a vida cotidiana do estudante para que ele possa finalizar o curso. Para Herbas-Torrico (2015), quando o estudante percebe um maior rendimento dos serviços que a universidade oferece, desenvolve sentimentos positivos e cresce sua satisfação com relação a ela.

No entanto, segundo Fernandes (2006), a real situação em que se encontra o estudante pode também interferir em suas escolhas. Além disso, ressaltam Dias e Soares (2012) que as possibilidades e condições de ingresso podem ser determinantes na hora de optar por uma instituição ou outra. Para BorgesAndrade e Bastos (2004), esse processo é ainda mais complexo dentro de uma 
sociedade capitalista, em que a classe socioeconômica influenciará os estudantes nessa decisão, pois reduz a liberdade de escolha. Para Dias e Soares (2012), a limitação ou direcionamento de decisões futuras quanto à carreira estão muitas vezes veladas no processo inicial de ingresso na Educação Superior.

\section{3 - AS QUESTÕES PROFISSIONAIS RETÊM MAIS DO QUE FAZEM OS ESTUDANTES DESISTIR}

Direta ou indiretamente, a escolha profissional tem reflexos sobre a identidade do indivíduo, sobre a maneira como se vê e interage com o seu entorno (VALORE, 2008). Entende-se que, dentro dessa compreensão, a profissão ocupa a função essencial de estabelecer uma conexão entre o trabalho e a vida pessoal. A formação profissional, que origina a inserção na Educação Superior, caracterizase, então, como um processo de aprendizagem em permanente desenvolvimento; representa cada vez mais um meio, não um fim. Então, a troca de curso ou até mesmo de IES tem deixado de ser vista como 'falha' no currículo, para ser encarada também como uma decisão que pode implicar maturidade. No entanto, o que esta pesquisa constatou é que, quando o estudante consegue conciliar sua preferência com sua realidade, a escolha mostra-se assertiva. A intenção de obter o diploma e de exercer uma profissão sobrepõe-se às dificuldades e limitações na trajetória acadêmica.

A categoria 'Profissional' aparece em primeiro lugar, entre os estudantes que atualmente cursam Engenharia e Tecnologia da Informação, para justificar a desistência pregressa; em segundo lugar, para os estudantes de Direito, e, em terceiro, para estudantes dos cursos de Educação Física, Matemática, Psicologia e Letras. No entanto, a categoria 'Profissional' não foi referida, em nenhuma posição, como justificativa para a desistência pregressa entre os estudantes dos cursos de Enfermagem e de Pedagogia.

A escolha profissional pode partir de uma motivação de natureza inconsciente ou de uma escolha autônoma e consciente, por determinantes individuais ou sociais. Conforme Valore (2008), leva em conta, sobretudo, preocupações com a profissão que será exercida, que podem ser: as taxas de desemprego, a concorrência acirrada no mercado, as aposentadorias em idade precoce, as condições impostas pelo contexto socioeconômico nacional e internacional, as inovações tecnológicas e científicas, o surgimento contínuo de novas ocupações, a crescente demanda por qualificação profissional, a desproporcionalidade entre o número de vagas no Ensino Superior e o número de candidatos, as mudanças nos critérios de empregabilidade, entre outros. A autora destaca ainda: 
Embora habitualmente associado à adolescência, o ato de decidir a respeito de uma ocupação profissional constitui momento de crise em qualquer época da vida, pois, não se trata apenas de executar novas tarefas e sim, de apropriar-se de uma nova identidade, a profissional. (VALORE, 2008, p. 66).

Mudanças na nova 'ordem' do trabalho estão afetando diretamente as pessoas, não somente enquanto profissionais, mas, também, em sua identidade, em seus valores, em seus projetos e em suas ações. Para Lisboa (2002), cada indivíduo possui sua capacidade de análise da situação e, dentro dos seus projetos e objetivos, luta para alcançar o que julga importante. Assim, dada uma realidade determinada, haverá reações e ações, que serão manifestadas por cada um.

\section{CONSIDERAÇÕES FINAIS}

Esta pesquisa analisou as motivações para o abandono e a permanência de estudantes na Educação Superior, a partir de uma amostra oriunda de uma IES privada do Sul do Brasil. Entre seus achados, evidenciou-se que, apesar de muitos estudantes nunca terem desistido efetivamente de algum curso de graduação iniciado, há um número significativo que já desistiu ou que pensa ou já pensou em desistir. Essas constatações são relevantes para a Educação, pois, ampliam a compreensão e as concepções sobre os possíveis motivos que levam ao abandono acadêmico, a partir da ótica dos estudantes, podendo servir como subsídio a possíveis alternativas para qualificar a vida universitária e promover políticas de permanência e conclusão do curso.

Parece essencial que as políticas voltadas à permanência na Educação Superior empreendam esforços para contemplar a realidade evidenciada em estudos empíricos que exploram a evasão acadêmica, considerando as realidades locais. Nesse sentido, no presente estudo, as subjetividades dos alunos, expressas na categoria Pessoal, foram as justificativas mais frequentes tanto para a permanência quanto para a evasão, demonstrando a necessidade de pesquisas direcionadas a esses aspectos, considerando, inclusive, o período de transição entre a Educação Básica e a Educação Superior. São imprescindíveis ações voltadas à preparação para o ingresso do aluno na IES, visando a aproximá-lo do conhecimento da realidade do curso e da profissão e reduzir possíveis dúvidas em relação à carreira pretendida.

A compilação das argumentações dos estudantes para o abandono ou para a permanência dando voz aos discentes fez emergir categorias e subcategorias, sendo esta uma das principais contribuições deste estudo. A compreensão de fenômenos multifatoriais como a evasão estudantil não pode ser realizada sem a aproximação com a realidade e a subjetividade de cada estudante; deve-se 
buscar conhecer e reconhecer suas necessidades, expectativas e queixas. Além disso, a generalização dessas informações é um processo que deve ser construído paulatinamente, no acúmulo de conhecimento que vai emergindo da replicação dos estudos. Nesse sentido, alertamos para a cautela na generalização dos resultados apresentados, pois são oriundos de uma realidade específica, em um momento determinado.

Como diretrizes futuras, aponta-se a relevância de pesquisar o contingente de estudantes que já deixaram a instituição, os evadidos, bem como, de comparar resultados oriundos de estudos com diferentes amostras, refletindo a diversidade que se apresenta no contexto da Educação Superior. Estudos que associem ou estabeleçam relações entre a percepção dos estudantes e dos gestores sobre o fenômeno da permanência e da evasão acadêmica representam também a oportunidade de se produzir um panorama global que direcione para ações efetivas voltadas à qualificação da Educação Superior.

\title{
REFERÊNCIAS
}

\begin{abstract}
ALMEIDA, M. R. Educação de Jovens e Adultos no Município de Senhor do Bonfim-BA: relação entre a prática docente e a evasão escolar. 2008. 86 f. Dissertação (Mestrado em Educação Agrícola) - Universidade Federal Rural do Rio de Janeiro, Seropédica, RJ, 2008.
\end{abstract}

BAGGI, C. A. S.; LOPES, D. A. Evasão e Avaliação Institucional no Ensino Superior: uma discussão bibliográfica. Avaliação, Campinas: Sorocaba: SP, v. 16, n.2, p.355-374, 2011.

BARRERA, O.; CASALLAS, P.; SASTRE, A. Factores asociados a la deserción estudiantil en la universidad piloto de colombia. V Conferência latino-americana sobre o abandono, V, Talca Universidad, Chile, 2015.

BORGES-ANDRADE, J. E.; BASTOS, A. V. B. Psicologia, organizações e trabalho no Brasil. Porto Alegre: Artmed, 2004.

BRASIL. Ministério da Educação e Cultura (MEC). Instituto Nacional de Estudos e Pesquisas Educacionais Anísio Teixeira (INEP). Resumo Técnico Censo da Educação Superior 2013. Brasília: INEP, 2013. Disponível em: < portal.inep. gov.br/web/censo-da-educacao-superior/resumos-tecnicos> 
BRITTO, L. P.L.; SILVA, E. O. S.; CASTILHO, K. C.; ABREU,T. M. Conhecimento e formação nas IES periféricas: perfil do aluno "novo" da educação superior. Avaliação, Campinas: Sorocaba, SP, v.13, n.3, p. 777-791, nov. 2008.

DIAS, M S.L.; SOARES, D. H.P. A escolha profissional no direcionamento da carreira dos universitários. Psicol. cienc. prof. [online], vol.32, n.2, p. 272-283, 2012. Disponível em:<http://www.scielo.br/scielo.php?script=sci_ arttext\&pid=S1414 98932012000200002\&lng=en\&nrm=iso $>$.

FERNANDES, D. C. Mitos familiares e escolha profissional: uma visão sistêmica. Psic. - Revista de Psicologia, São Paulo: Vetor Editora, v. 7, no 1, p. 99-100, jan. /jun. 2006.

FRIEGEBEN, L.E. G.; DIAZ, O. E.; FERNÁNDEZ, L. L. Deserción y fracasso acadêmico en la educación superior en América Latina y el Caribe: resultados e implicancias. In: Una Visión Integral del Abandono. SANTOS, B. S. et al. (Org). Porto Alegre: Edipucrs, 2013.

HERBAS-TORRICO, B. C. La Influencia de la motivación y la satisfacción de los estudiantes en sus intenciones de graduación. In: V Conferência latinoamericana sobre o abandono, V, Talca Universidad, Chile, 2015.

KARABEL, J. Community colleges and social stratification. Harvard Educational Review, 42(4), 521 -562, 1972.

KIRA, L. P. A evasão no ensino superior: o caso do curso de pedagogia da Universidade Estadual de Maringá (1992-1996). 2002. 106 f. Dissertação (Mestrado em Educação) -Universidade Metodista de Piracicaba, São Paulo, 2002.

LISBOA, M. D. Orientação profissional e mundo do trabalho: Reflexões sobre uma nova proposta frente a um novo cenário. In: LEVENFUS R. S.; SOARES, D.H.P. (Orgs.). Orientação vocacional ocupacional: Novos achados teóricos, técnicos e instrumentais para a clínica, a escola e a empresa. Porto Alegre: Artes Médicas, p. 33-49, 2002.

LOBO, M. B. C. M. Panorama da Evasão no Ensino Superior Brasileiro: Aspectos Gerais das Causas e Soluções. Associação Brasileira de Mantenedoras de Ensino Superior, cadernos no 25, p. 1-23, dez. 2012. Disponível em <http:// www.institutolobo.org.br/imagens/pdf/artigos/art_087.pdf> 
MATUS, O.; LANDA, V.; KUHNE, W.; PAINEPAN, B. Fracaso académicos en estudiantes de ingeniería desde la mirada del desarrollo personal: estudio longitudinal. In: V conferência latino-americana sobre o abandono, V, Talca Universidad, Chile, 2015.

MOROSINI, Marília Costa, et al. A evasão na Educação Superior no Brasil: uma análise da produção de conhecimento nos periódicos Qualis entre 20002011. In: II Conferência latino-americana sobre o abandono, II, Pontifícia Universidade Católica do Rio Grande do Sul, Brasil, 2012.

MEC/ANDIFES/ABRUEM/SESU. Diplomação, retenção e evasão nos cursos de Instituições de Ensino Superior Públicas. Relatório da ComissãoEspecial para Estudos sobre a Evasão nas Universidades públicas Brasileiras, Brasília: MEC Secretaria de Educação Superior; Estudo, out. 1997. Disponível em: <http://www.udesc.br/arquivos/id_submenu/102/diplomacao.pdf. >

MORAES, R. Uma experiência de pesquisa coletiva: introdução à análise de conteúdo. In: GRILLO, M. C.; MEDEIROS, M. F. (Orgs). A construção do conhecimento e sua mediação metodológica. Porto Alegre: EDIPUCRS, p. 111-128, 1998.

POLYDORO, S. A. O trancamento de matrícula na trajetória acadêmica no universitário: condições de saída e de retorno à instituição. 2000. 145 f. Tese (Doutorado em Educação) - Universidade Estadual de Campinas, Campinas, 2000 .

PROYECTO Alfa Guia Dci-Alfa/2010/94. Proyecto ALFA-III “Gestión Universitaria Integral del Abandono. Construcción colectiva del concepto de abandono en la educación superior para su medición y análisis. Alfa Guia: Coordinadores: Jesús Arriaga (Universidad Politécnica de Madrid) Melbin Velásquez (Universidad de Antioquia) Grupo Análisis, nov. 2013. Disponível em: <http://www.alfaguia.org/wwwalfa/images/resultados/Marco_Conceptual_ sobre_el-Abandono.pdf $>$

ROOTMAN, I. Voluntary withdrawal from a total adult socialization organization: A model. Sociology of Education, 45, 258-270, 1972.

SANTOS, B. S. dos; MOROSINI, M. C.; COFER, J. Fatores de Persistência de Estudantes de uma Universidade Particular Brasileira. In: IV Conferência 
latino-americana sobre o abandono, IV, Universidad de Antioquia, Medellin, Colômbia, 2014.

TINTO, V. Definir la deserción: una cuestión de perspectiva. Revista de Educación Superior, México: ANUIES, nº 71, p. 1-9, 1989.

TINTO, Vincent. Dropout from higher education: a theoretical synthesis of recent research. Review of Educational Research: Washington, v. 45, n.1, p.89$125,1975$.

VALORE, L.A. A problemática da escolha profissional: as possibilidades e compromissos da ação psicológica. In: SILVEIRA, A. F.et al. (org). Cidadania e participação social [online]. Rio de Janeiro: Centro Edelstein de Pesquisas Sociais, p. 66-76, 2008. Disponível em: SciELO Books <http://books.scielo.org>

BETTINA STEREN DOS SANTOS possui graduação em Pedagogia pela UFRGS (1989) e doutorado em Psicologia Evolutiva e da Educação - Universidad de Barcelona (1996). Pós-doutorado no College of Education, The Univesity of Texas at Austin, EUA. É professora e coordenadora do Grupo de Pesquisa "Processos Motivacionais em Contextos Educativos" da Escola de Humanidades - Educação/PUCRS. Coordenadora do Curso de Especialização em Psicopedagogia e é Bolsista de Produtividade em Pesquisa - PQ/CNPq. Tem experiência na área de Psicologia Educativa, com ênfase nos processos de ensino e aprendizagem, atuando principalmente nos seguintes temas: formação de professores, processos motivacionais, mal-estar e bem-estar docente; metodologias de ensino. Atualmente é Decana Associada da Escola de Humanidades da PUCRS. E-mail: bettina@pucrs.br

TÁRCIA RITA DAVOGLIO é Graduada em Psicologia - Habilitação para Psicólogo e Licenciatura Plena, Especialista em Psicoterapia Psicanalítica, com formação em psicopatologia do bebe (Universite Paris 13). Mestre em Psicologia Clínica, Doutora em Psicologia, com ênfase em avaliação psicológica e personalidade. Pesquisadora em estágio pós-doutoral (Edital DOCFIX/FAPERGS/ CAPES/2012) no Programa de Pós-Graduação em Educação/PUCRS. Professora na Escola de Humanidades/PUCRS, na Faculdade Meridional IMED/Passo Fundo e na Fundação Universitária de Cardiologia/Porto Alegre. Coordenadora do Grupo de Pesquisa Psicologia Aplicada: Pessoa e Contextos e pesquisadora colaboradora do grupo de pesquisa PROMOT/PUCRS. E-mail: tarciad@gmail.com 
CARLA DA CONCEIÇÃO LETTNIN é professora de Educação Física do Departamento de expressão e movimento do Colégio de aplicação da UFRGS; Mestre em Teoria e Prática Pedagógica em Educação Física e Doutora em Educação; Coordenadora do grupo de pesquisa Educação e Saúde do CNPQ. E-mail: carla.lettnin@ufrgs.br

CARLA SPAGNOLO é licenciada em Educação Física pela Universidade de Caxias do Sul, Mestre em Educação pela Pontifícia Universidade Católica do Rio Grande do Sul, Doutoranda em Educação pela mesma instituição. Tem experiência como professora e gestora em Escolas de Educação Básica. Realizou Estágio de Doutorado Sanduíche na Universidade de Barcelona - Espanha, por um período de nove meses. Atua como professora em cursos de pós-graduação em educação com a temática de ensino e de aprendizagem e em cursos utilizando a metodologia criativa do Design Thinking. Atualmente é bolsista e faz parte de grupos de pesquisa da Pucrs, como PROMOT (Processos Motivacionais). E-mail: carla.spangolo@acad.pucrs.br

LORENA MACHADO DO NASCIMENTO é mestranda em Educação, graduada em Pedagogia na Pontífícia Universidade Católica do Rio Grande do Sul (PUCRS). Membro do grupo de pesquisa PROMOT - Processos Motivacionais em Contextos Educativos, coordenado pela professora Dra. Bettina Steren dos Santos da PUCRS. E da rede RIES - Rede Sulbrasileira de Investigadores em Educação Superior, coordenada pela Dra. Profa. Marília Costa Morosini, que trabalha com investigações sobre Contextos Emergentes em Educação Superior. Tem grande experiência na área de Educação Infantil, com ênfase em Planejamento Educacional e coordenação de equipe. E-mail: lorena. nascimento@acad.pucrs.br 